\title{
CAPÍTULO 33: PALMA E CHIA UTILIZADOS COMO SUBSTITUTOS DEESTABILIZANTES EM SORVETE DE UMBU
}

\section{CHAPTER 33: PALMA AND CHIA USED AS SUBSTITUTES FOR STABILIZERS IN UMBU ICE CREAM}

\author{
José Iago dos santos Aragão ${ }^{1}$; Anny Kelly Vasconcelos de Oliveira Lima²
}

\begin{abstract}
Resumo
O objetivo deste estudo foi o desenvolvimento de um sorvete, a fim de avaliar a viabilidade do emprego da mucilagem de chia e palma em substituição ao estabilizante liga neutra. O processo de elaboração ocorreu em três etapas: desenvolvimento do produto, caracterização física e físico-química. Foi elaborado um delineamento estatístico (DCCR), onde foram desenvolvidas doze diferentes formulações. Após testes preliminares, foram selecionadas cinco formulações: F1 (30 g de chia); F2(30g de palma); F3 (42,6 g de chia + 17,4 de palma) e F4 (17,4g de Chia + 42,6g de palma) e F5 controle (15,2g de liga neutra), foram realizadas análises de acidez titulável; potencial hidrogeniônico $(\mathrm{pH})$; sólidos solúveis; overrun e derretimento. As formulações quando comparadas com a controle apresentaram resultados satisfatórios, quanto a taxa de derretimento e overrun. Dessa maneira pôde-se afirmar que para o sorvete de umbu substituindo o estabilizante industrial pelo estabilizante natural de origem vegetal está dentro dos padrões estabelecidos na legislação vigente para overrun, sólidos solúveis e derretimento.

Palavras-chave: Salvia hispanica; Gelados comestíveis; Opuntia ficus-indica.
\end{abstract}

\begin{abstract}
The aim of this study was the development of an ice cream, in order to assess the viability of using chia and palm mucilage to replace the neutral alloy stabilizer. The elaboration process took place in three stages: product development, physical and physical-chemical characterization. A statistical design (DCCR) was developed, in which twelve different formulations were developed. After preliminary tests, five formulations were selected: F1 (30g of chia); F2 (30g of palm); F3 (42.6 g of chia +17.4 palm) and F4 (17.4 g of Chia $+42.6 \mathrm{~g}$ of palm) and F5 control (15.2 g of neutral alloy), titratable acidity analyzes were performed; hydrogen potential $(\mathrm{pH})$; soluble solids; overrun and melt. The formulations when compared to the control showed satisfactory results, as far as the rate of melting and overrun. In this way it could be said that for umbu ice cream replacing the industrial stabilizer with the natural stabilizer of plant origin it is within the standards established in the current legislation for overrun, soluble solids and melting.
\end{abstract}

Keywords: Salviahispanica; Edible ices; Opuntia ficus-indica.

\footnotetext{
${ }^{1}$ Bacharelado em Agroindústria, Universidade Federal de Sergipe- UFS Campus Sertão, iagoaragao7@ gmail.com

2 Professora Doutora, Núcleo de graduação em Agroindústria, Universidade Federal de Sergipe- UFS Campus Sertão, annykellyv@gmail.com
} 


\section{Introdução}

Gelados comestíveis, também denominados sorvetes, são sobremesas cujo consumo vem crescendo nos últimos anos, sobretudo aqueles modificados. Consistem em um sistema coloidal, que forma emulsão com gotículas de gordura, proteínas, ar e cristais de gelos dispersos na fase aquosa (ALMEIDA, et al. 2016).

O sorvete recebe designações diversas de acordo com sua composição ou quanto a sua técnica de fabricação e apresentação. Do ponto de vista nutricional, o sorvete é tido como um alimento completo com elevado valor nutritivo, pois além de fornecer proteínas, carboidratos, lipídeos, cálcio, fósforo e outros minerais é rico em vitaminas A, B1, B2, B6, C, D, E e K (ARBUCKLE, 1986).

O mercado brasileiro de sorvetes tem se tornado cada vez mais atrativo e a prova disso é que o país já é o sexto maior produtor mundial estando atrás dos Estados Unidos, China, Rússia, Japão e Alemanha. Segundo a Associação Brasileira das Indústrias e do Setor de Sorvetes (Abis), embora o consumo per capita ainda seja de 5,44 litros/ano a perspectiva é que este produto ganhe cada vez mais relevância na economia. Ainda de acordo com a Abis, a estimativa é que a indústria de sorvetes cresça de 3\% a 5\% em 2019. O mercado de sorvetes exige renovação constante, dinamismo e a oferta de novas opções aos consumidores (ABIS, 2019).

Os sorvetes atendem uma demanda de produtos especialmente modificados, acolhendo aos consumidores com alguma restrição alimentar, como os diabéticos e os intolerantes à lactose, além daqueles com adição de ingredientes funcionais. Esses ingredientes, por sua vez, conferem efeitos adicionais à saúde, cujas características são relativas ao papel metabólico ou fisiológico do componente sobre o crescimento, desenvolvimento, manutenção e outras funções normais do organismo humano. Dentre os ingredientes em que suas alegações de saúde têm sido estudadas destaca-se a chia, cuja ingestão resulta em efeitos benéficos à saúde, além de melhorar o valor nutritivo do produto. A chia possui alto índice de ômega 3, cálcio, fósforo, fibras, proteínas e sobretudo sua adição não tem influência nas características organolépticas do produto. Ajuda a reduzir os níveis de triglicerídeos, ótima fonte de proteína vegetal, reduz o risco de diabetes, anti-inflamatório e contém todos aminoácidos essenciais (COATES \& AYERZA, 1996).

O umbu, no entanto, é outra matéria-prima nutritiva, considerada uma fruta rica em vitamina $\mathrm{C}$, e além disso possuir um excelente sabor e aroma, apresenta também boa aparência e qualidade nutritiva, essa fruta chega a apresentar em média $68 \%$ de rendimento em polpa, podendo ser consumida in natura na forma de sucos e refrescos, bem como em sorvetes. $\mathrm{O}$ 
umbu é explorado de forma extrativista, o que constitui uma excelente fonte de renda complementar para as comunidades locais, em virtude da crescente demanda por frutos tropicais. (NEVES et al. 2005; CARVALHO et al. 2008).

A palma forrageira (Opuntia ficus-indica Mill) é uma planta típica de regiões semiáridas, cultivada principalmente para alimentação de animais em épocas de estiagem, podendo também ser utilizada na alimentação humana (BEZERRA et al., 2012). Essa planta pode ainda ser utilizada como antioxidante, agente anti-inflamatório e na prevenção de úlceras devido às suas propriedades medicinais (LEE et al., 2002).

Teixeira et al., (1999) ressalta que bem adaptada morfologicamente às intempéries do semiárido, a palma possui grande quantidade de água, é rica em resíduos minerais como cálcio, magnésio, sódio e potássio e vitaminas A, C e do complexo B, apresentando elevado teor de carboidratos solúveis além de alto coeficiente de digestibilidade da matéria seca. Vale lembrar que o reconhecimento do valor nutricional da palma tem motivado, nos últimos anos, o desenvolvimento de trabalhos, objetivando introduzir a verdura de palma na dieta alimentar do nordestino.

Adicionar ingredientes com elevado valor nutricionais, sem comprometer o sabor dos alimentos, é uma prática de relevância para se constituir uma dieta saudável. Nesse contexto a chia é particularmente interessante, pois além de melhorar o valor nutricional, é uma importante matéria-prima quando se fala em elaborar alimentos funcionais (COATES \& AYERZA, 1996). Sobretudo sua adição não tem influência nas características organolépticas do produto. Ajuda a reduzir os níveis de triglicerídeos, ótima fonte de proteína vegetal, reduz o risco de diabetes, anti-inflamatório e contém todos aminoácidos essenciais.

A obtenção de sorvetes pela mistura de leite integral, polpa de palma, polpa de umbu e semente de chia, pode resultar em um produto com qualidade nutricional e potencialmente funcional com características sensoriais atrativas. Sendo a ideia de substituir parcialmente ou totalmente o estabilizante (liga neutra) pela chia, e a adição da polpa da palma com o intuito de enriquecer o produto, mostra-se merecedora de um estudo mais aprofundado, que poderá ampliar a gama de opções de produtos a serem formulados com a adição de tais ingredientes.

\section{Metodologia}

O estudo foi desenvolvido na Universidade Federal de Sergipe - Campus do Sertão, no laboratório multidisciplinar 03, em Nossa Senhora da Glória - Sergipe. O desenvolvimento deste estudo compreendeu as seguintes fases: seleção da matéria-prima, elaboração de diferentes ensaios do sorvete e caracterização das diferentes formulações. 


\section{Material}

Para a preparação do sorvete foram utilizadas as seguintes matérias-primas: leite integral, leite em pó, açúcar, creme de leite, estabilizantes, emulsificante, polpa de umbu, polpa de palma e chia.

A palma forrageira utilizada no estudo foi proveniente da propriedade rural do próprio autor localizada no município de Nossa Senhora da Glória - Sergipe.

Os demais ingredientes foram adquiridos no comércio local da Cidade de Nossa Senhora da Glória -SE, com exceção do leite integral e do creme de leite os quais foram fornecidos pela empresa Betânia Lácteos localizada no município supracitado.

\section{Obtenção das mucilagens Mucilagem de chia}

Para a obtenção da mucilagem, as sementes foram submersas em água destilada na concentração de semente/água: 1:40 (peso:volume) e deixou-se em descanso por cerca de 90 min. Para a extração da mucilagem, que fica fortemente aderida à superfície da semente, empregou-se um mixer de $500 \mathrm{~W}$ de potência da marca Mondial, durante um período de 60 segundos. Para evitar o rompimento das sementes, as lâminas do mixer foram recobertas com fita adesivas. A mucilagem então foi separada da semente através de filtração em peneira simples (adaptado de MUNOZ, 2012).

\section{Mucilagem de palma}

Os cladódios de palma forrageira foram coletados nas primeiras horas do dia, acondicionados em bandejas plásticas e em seguida transportados até o laboratório, os cladódios foram lavados em água corrente e em seguida retirou-se, os acúleos (falsos espinhos) utilizando facas de aço inoxidável. Logo após foram imersos numa solução de hipoclorito de sódio a 100 ppm por 10 minutos e enxaguados, para a retirada do excesso de cloro. Os cladódios foram cortados e triturados em um liquidificador da marca Mondial e peneirados para a remoção dos fragmentos fibrosos e grossos. Após o processo de extração a mucilagem foi congelada (Adaptado de OLIVEIRA, 2015).

\section{Formulação do gelado comestível}

As formulações de sorvete foram elaboradas de acordo com o diagrama de produção apresentado na Figura 1 e processadas seguindo as normas de Boas Práticas de Fabricação (BPF). 
Figura 1. Diagrama de produção do sorvete.

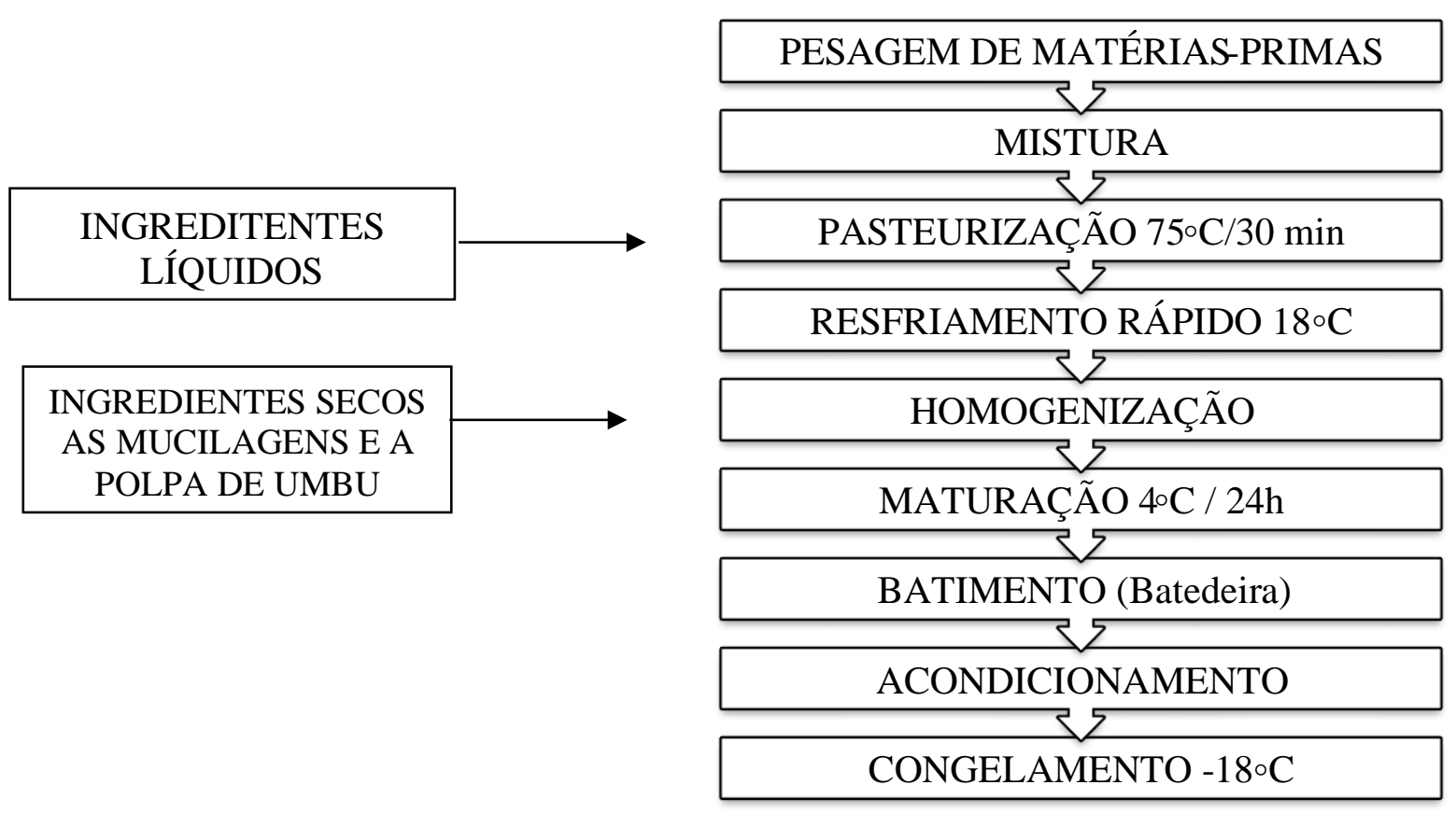

Fonte: Adaptado de Freitas, 2012.

As massas dos ingredientes foram medidas separadamente em balança digital eletrônica de precisão Sf-400. O leite e o creme de leite foram alocados em recipiente, e então pasteurizados em fogão convencional. Quando a mistura, leite e creme de leite atingiu $75^{\circ} \mathrm{C}$, a temperatura foi mantida por 15 minutos para que ocorresse a pasteurização lenta.

Após decorrido este tempo a mistura passou por um resfriamento, até que atingisse a temperatura de $18^{\circ} \mathrm{C}$, onde o recipiente da mistura foi submetido a outro recipiente contendo água gelada e gelo. Em seguida foram adicionados os ingredientes secos (leite em pó e açúcar), as mucilagens (para cada tratamento) e a polpa do umbu, e iniciou o processo de homogeneização com uso de liquidificador tradicional, por um tempo de 5 a 8 min, onde foi obtida uma calda. Logo após o processo de homogeneização a calda foi resfriada a $4^{\circ} \mathrm{C}$ por 24 h, ocorrendo a maturação.

Passado esse tempo, a calda já congelada foi submetida a batedeira junto com o emulsificante, onde ocorreu o processo de batimento por cerca de 15 minutos, para que fosse incorporado o ar e a calda então se transformasse em sorvete.

Após o sorvete pronto, o mesmo foi acondicionado em baixa temperatura $\left(-18^{\circ} \mathrm{C}\right)$ para que finalizasse o processo de congelamento, sendo mantido nesta temperatura até o momento das análises. 


\section{Planejamento experimental}

\section{Experimento inicial}

Inicialmente, utilizou-se o delineamento composto central rotacional (DCCR) $2^{2}$ (Tabela 1), foram preparadas nove diferentes formulações de sorvetes, onde misturou-se diferentes níveis das variáveis independentes "mucilagem de chia" e "mucilagem de palma". Conforme pode ser visualizado na tabela citada. O delineamento incluiu três formulações no ponto central $(0,0)$ para que fosse possível estimar a falta de ajuste dos modelos preditivos calculados.

Os limites inferiores e superiores das variáveis independentes mucilagem de chia e mucilagem de palma utilizados no experimento foram definidos com base nos estudos de Campos et al. (2015), Fukase (2017), Bernardino-Nicanor et al. (2015), Medina-Torres et al., (2003).

Tabela 1. Matriz do delineamento experimental utilizado para formulação do sorvete, com os valores reais e codificados das variáveis independentes.

\begin{tabular}{ccccc}
\hline Tratamentos & \multicolumn{2}{c}{ Variáveis codificadas } & \multicolumn{2}{c}{ Variáveis descodificadas } \\
\hline $\mathbf{1}$ & $\begin{array}{c}\text { Mucilagem de } \\
\text { Chia }\end{array}$ & $\begin{array}{c}\text { Mucilagem } \\
\text { de Palma }\end{array}$ & $\begin{array}{c}\text { Mucilagem de } \\
\text { Chia }(\%)\end{array}$ & $\begin{array}{c}\text { Mucilagem de } \\
\text { Palma (\%) }\end{array}$ \\
\hline $\mathbf{2}$ & -1 & -1 & 0,87 & 0,87 \\
\hline $\mathbf{3}$ & -1 & 1 & 2,13 & 0,87 \\
\hline $\mathbf{4}$ & 1 & -1 & 0,87 & 2,13 \\
\hline $\mathbf{5}$ & 1 & 1 & 2,13 & 2,13 \\
\hline $\mathbf{6}$ & $-1,4142$ & 0 & 0,00 & 1,50 \\
\hline $\mathbf{7}$ & 1,4142 & 0 & 3,00 & 1,50 \\
\hline $\mathbf{8}$ & 0 & $-1,4142$ & 1,50 & 0,00 \\
\hline $\mathbf{9}$ & 0 & 1,4142 & 1,50 & 3,00 \\
\hline $\mathbf{1 0}$ & 0 & 0 & 1,50 & 1,50 \\
\hline $\mathbf{1 1}$ & 0 & 0 & 1,50 & 1,50 \\
\hline $\mathbf{1 2}$ & LIGA NEUTRA & & 1,50 & 1,50 \\
\hline & & & & \\
\hline & & 0 & & \\
\hline
\end{tabular}

\section{Análises físico-químicas}

Foram realizadas análises em triplicata de acidez titulável $\left({ }^{\circ} \mathrm{D}\right)$, potencial hidrogeniônico $(\mathrm{pH})$ e sólidos solúveis $\left({ }^{\circ} \mathrm{Brix}\right)$, seguindo a metodologia preconizados pelas 
Normas Analíticas do Instituto Adolfo Lutz (2008). As formulações elaboradas também foram analisadas quanto à taxa de derretimento e overrun, de maneira adaptadas (SOLER \& VEIGA 2001).

O teor de acidez foi expresso em porcentagem (\%) de ácido láctico e os testes foram realizados por titulação, com a utilização de hidróxido de sódio e fenolftaleína.

$\mathrm{O} \mathrm{pH}$ das amostras foi determinado por phmetro digital de bancada previamente calibrado com solução tampão, indicando um valor preciso a temperatura ambiente.

O teor de sólidos solúveis foi determinado pelo uso de um refratômetro. As amostras foram inseridas em pequenas quantidades no equipamento e realizadas a leitura, contendo o resultado em grau Brix seguindo o método descrito pelo instituto Adolfo Lutz (2008).

Para indicar o ponto de derretimento foi utilizado a adaptação da metodologia de Granger et al. (2005). Em uma balança analítica, foi pesado aproximadamente $50 \mathrm{~g}$ de cada formulação em uma tela com abertura de $0,2 \mathrm{~cm}$ disposta sobre um béquer de vidro, na qual a amostra foi colhida à medida que ocorria o derretimento. Desta forma foram realizadas pesagens do sorvete a cada 10 minutos no período de 50 minutos. Para a realização do experimento, as condições de temperatura foram mantidas idênticas $\left(19^{\circ} \mathrm{C}\right)$, para as formulações, com o intuito de tornar mínima sua influência sobre o derretimento e consequentemente sob os resultados finais.

Para determinação do overrun foi empregada a equação descrita por Soler \& Veiga (2001), conforme apresentado abaixo:

\section{$\%$ OVERRUN $=$ VOLUME DO SORVETE - VOLUME DA CALDA $* 100$ VOLUME DA CALDA}

\section{Análises físico e físico-químicas iniciais}

Para as formulações iniciais elaboradas, foram analisadas as propriedades físico e físicoquímicas. A partir dos resultados obtidos, foram selecionadas as 5 formulações que apresentaram melhores índices de overun, sólidos solúveis e derretimento, para a condução da pesquisa, foram elas (Tabela 2): 
Tabela 2. Formulações selecionadas quanto às características de sólidos solúveis, overrun e derretimento.

Tratamentos Mucilagem de Chia Mucilagem de Palma *Citação no texto

(g)

(g)

\begin{tabular}{cccc}
\hline $\mathbf{1}$ & 42,6 & 17,4 & $\mathrm{C}+\mathrm{P}-$ \\
\hline $\mathbf{2}$ & 17,4 & 42,6 & $\mathrm{C}-\mathrm{P}+$ \\
\hline $\mathbf{3}$ & 0,00 & 30,0 & $\mathrm{P}$ \\
\hline $\mathbf{4}$ & 30,0 & 0,00 & $\mathrm{C}$ \\
\hline $\mathbf{5}$ & 0,00 & 0,00 & Controle
\end{tabular}

*C+P-: Maior quantidade de chia e menor de palma; C-P+: Maior quantidade de palma e menor de chia; $\mathrm{P}$ : Apenas palma; C: Apenas chia; C: Controle

Depois da seleção das melhores formulações, foi elaborado um delineamento estatístico inteiramente casualizado (DIC), com 5 tratamentos e 3 repetições, em que novamente as análises: acidez titulável, potencial hidrogeniônico $(\mathrm{pH})$ e sólidos solúveis, overrun e derretimento foram aplicadas.

\section{Análise estatística}

Os dados obtidos foram analisados com o auxílio do programa estatístico SISVAR e do Software LIBRIOFFICE 6.1. O teste ANOVA (nível de significância de 5\%), foi usado com o intuito de averiguar se houve diferença significativa entre as amostras. O teste de Tukey foi aplicado, para indicar as diferenças entre as médias.

\section{Resultados e Discussão}

\section{Análises físico-químicas e físicas Determinação de acidez}

De acordo com o Instituto Adolfo Lutz (2008), a análise de acidez titulável gera dados fundamentais do estado de conservação de um produto alimentício. Nessa pesquisa, o índice de acidez, foi maior para a formulação controle, porém na formulação 2, onde se utilizou maior quantidade de palma que de chia, o valor de acidez também esteve elevado. Tal parâmetro em sorvetes pode ser influenciado pela composição da mistura, ou seja, pela adição de leites de diferentes origens e pela utilização de frutas na formulação (GANDOLFI \& MULLER, 2014). Não existe legislação no momento, com valores de referência para a acidez titulável em sorvetes, porém as indústrias utilizam a acidez do leite como um dos parâmetros para o controle da matéria-prima (BRASIL, 2005). 
Tabela 3. Médias da acidez nas formulações de sorvete

\begin{tabular}{ccc}
\hline Tratamentos & *Formulações & Acidez \\
\hline $\mathbf{1}$ & $\mathrm{C}+\mathrm{P}-$ & $0.400 \mathrm{bc}$ \\
\hline $\mathbf{2}$ & $\mathrm{C}-\mathrm{P}+$ & $0.406 \mathrm{~b}$ \\
\hline $\mathbf{3}$ & $\mathrm{P}$ & $0.386 \mathrm{bc}$ \\
\hline $\mathbf{4}$ & $\mathrm{C}$ & $0.383 \mathrm{c}$ \\
\hline $\mathbf{5}$ & Controle & $0.663 \mathrm{a}$
\end{tabular}

*C+P-: Maior quantidade de chia e menor de palma; C-P+: Maior quantidade de palma e menor de chia; P: Apenas palma; C: Apenas chia; C: Controle

Se considerar a acidez do leite entre 0,14 e 0,18 g de ácido lático em $100 \mathrm{~mL}$, os valores obtidos para as cinco formulações foram superiores, conforme estabelecido na Instrução Normativa $n^{\circ}$. 76/2018 (BRASIL, 2018). Silva (2013) elaborou um sorvete de umbu (Spondias tuberosa) e Umbu Cajazeira (Spondias sp), e reportou valores superiores aos estabelecidos pela IN $n^{\circ} .76 / 2018$, de 0,39\% ácido lático para o umbu e 0,60 \% de ácido lático para o umbu cajá resultados semelhantes aos encontrados nesta pesquisa. Pinto (2017), desenvolveu um sorvete a base de polpa de mandacaru e xique-xique que são cactáceas como a palma, e encontrou valores médios entre 0,21 a 0,32 .

Gandolf (2014) elaborou um sorvete com chia e mel e obteve resultados que variaram entre 0,12 a 0,126 (\% ácido lático), bem inferiores aos encontrados nesta pesquisa, o que reforça a ideia que a acidez do produto se dá pela escolha da matéria prima, já que o mel não se classifica como um produto de alta acidez. Os resultados aqui obtidos foram superiores, em todas as formulações, aos encontrados na literatura e nas normativas, o que certamente se deve ao fato do fruto do umbu assim como as frutas do gênero spondias, possuir alta acidez o que resultou em produtos com características ácidas.

\section{Determinação do Potencial hidrogeniônico (pH)}

O potencial hidrogeniônico das formulações de sorvete foram próximos a neutralidade em média 5,05. (Tabela 4)

Tabela 4. pH médio nas formulações de sorvete

\begin{tabular}{ccc}
\hline Tratamentos & *Formulações & $\mathrm{pH}$ \\
\hline $\mathbf{1}$ & $\mathrm{C}+\mathrm{P}-$ & $5,030 \mathrm{bc}$ \\
\hline $\mathbf{2}$ & $\mathrm{C}-\mathrm{P}+$ & $5,013 \mathrm{c}$ \\
\hline $\mathbf{3}$ & $\mathrm{P}$ & $5,070 \mathrm{ab}$ \\
\hline $\mathbf{4}$ & $\mathrm{C}$ & $5,086 \mathrm{a}$ \\
\hline $\mathbf{5}$ & Controle & $5,080 \mathrm{ab}$ \\
\hline
\end{tabular}

*C+P-: Maior quantidade de chia e menor de palma; C-P+: Maior quantidade de palma e menor de chia; P: Apenas palma; C: Apenas chia; C: Controle 
$\mathrm{O}$ pH dos sorvetes analisados tiveram uma variação de 5,013 a 5,086 e apresentaram semelhança significativa em todos os tratamentos $(\mathrm{p}<0,05)$, exceto entre as formulações 2 (maior conteúdo de palma) e 4 (só chia na formulação) as quais apresentaram respectivamente o menor e o maior índice de pH nas amostras (Tabela 4). No Brasil a legislação no 266 de 2005 não menciona valores de pH como referência para sorvetes (BRASIL, 2005).

Fidelis et al. (2015) elaborou um sorvetes de Mandacaru (Cereus jamacaru) e Figo da Índia (Opuntia fícus indica L. Mill), e encontrou um valor de 3,09, no entanto os valores de pH encontrados nesta pesquisa foram maiores, já quando comparados com os valores encontrados na pesquisa de Pinto (2017) onde o autor elaborou um sorvete de polpa de mandacaru e xiquexique e obteve valores de $\mathrm{pH}$ variando de 5,8 a 6,19, os valores de $\mathrm{pH}$ obtidos aqui foram menores. Certamente a elevação do $\mathrm{pH}$ das amostras se dá ao fato de que a polpa de umbu congelada, como a utilizada neste estudo, possui um pH em torno de $(4,34)$ (RODRIGUES, et al. 2010).

$\mathrm{Na}$ literatura não foi encontrado pesquisas que relatem o uso de chia e palma em sorvetes, o que impossibilita confirmações de outros estudos. Porém através desse estudo e de pesquisas sobre as duas matérias primas mencionadas, foi possível observar que tanto a palma quanto a chia influenciam no pH do sorvete. Gusmão (2016) encontrou na mucilagem de chia valor de pH de 7,06 e a palma de acordo com Queiroz (2020) possui um pH de 4,46.

\section{Determinação dos sólidos solúveis (SS)}

A quantidade de sólidos solúveis (SS) entre todas as formulações não diferiu estatisticamente entre si (Tabela 5).

Tabela 5. Médias da análise de Sólidos solúveis (SS) nas Formulações de sorvete

\begin{tabular}{ccc}
\hline Tratamentos & *Formulações & Sólidos solúveis $\left({ }^{\circ}\right.$ Brix $)$ \\
\hline $\mathbf{1}$ & $\mathrm{C}+\mathrm{P}-$ & $35.6 \mathrm{a}$ \\
\hline $\mathbf{2}$ & $\mathrm{C}-\mathrm{P}+$ & $35.3 \mathrm{a}$ \\
\hline $\mathbf{3}$ & $\mathrm{P}$ & $35.3 \mathrm{a}$ \\
\hline $\mathbf{4}$ & $\mathrm{C}$ & $36.0 \mathrm{a}$ \\
$\mathbf{5}$ & Controle & $35,0 \mathrm{a}$
\end{tabular}

*C+P-: Maior quantidade de chia e menor de palma; C-P+: Maior quantidade de palma e menor de chia; P: Apenas palma; C: Apenas chia; C: Controle

Certamente, esses valores encontrados nas formulações estudadas se devem, às várias fontes de açúcar encontradas no produto, como o açúcar adicionado como parte da receita, o açúcar da polpa de umbu, e do o açúcar do leite. Em relação à legislação, todas as formulações 
apresentaram valores acima do mínimo estabelecido pela legislação vigente que é de $28 \%$ (BRASIL, 2005).

Os sólidos solúveis (SS) obtidos nesta pesquisa foram superiores aos valores observados no estudo de Fidelis et al. (2015), que produziram sorvetes e iogurtes a partir dos frutos de figo da índia e mandacaru e encontraram um índice de 21,66 ${ }^{\circ}$ Brix. Clarke (2005) reportou que os teores de sólidos solúveis em sorvetes convencionais elaborados com leite variam de $28 \%$ a $40 \%$, que corrobora com os valores encontrados neste estudo.

\section{Análises físicas}

\section{Overrun}

As formulações contendo as mucilagens de chia e palma apresentaram comportamento de overrun semelhantes (superior a 50\%). As formulações F1 e F4, que utilizavam mais chia na preparação, apresentaram um rendimento próximo da formulação controle F5, enquanto aquelas formulações com maior quantidade de palma apresentaram menor rendimento quando comparados as outras (Figura 2). O overrun é considerado uma das etapas mais importantes da elaboração de sorvetes, pois o mesmo influencia diretamente na sua qualidade e no rendimento (SOLER, 2001).

De acordo com a Resolução RDC n ${ }^{\circ} 266$, de 22 de setembro de 2005, os sorvetes podem conter no máximo $110 \%$ de ar incorporado no produto, não havendo um mínimo exigido (BRASIL, 2005). Dessa maneira, os sorvetes elaborados estão dentro do padrão estabelecido pela legislação vigente.

Figura 2- Taxa de rendimento do sorvete

\section{Rendimento do sorvete (\%)}

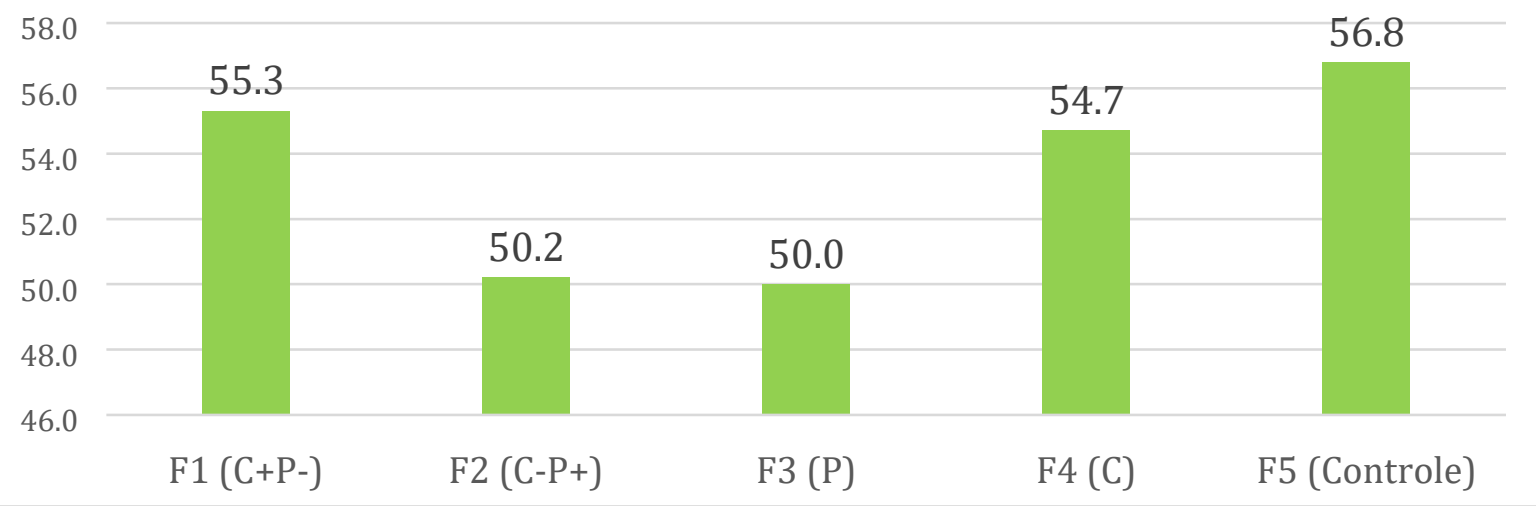

*C+P-: Maior quantidade de chia e menor de palma; C-P+: Maior quantidade de palma e menor de chia; $\mathrm{P}$ : Apenas palma; C: Apenas chia; C: Controle 
Os sorvetes comerciais geralmente possuem uma incorporação de ar em torno de 60 a 100\% (FELLOWS, 2006), assim a utilização do estabilizante natural em substituição ao industrial apresentou resultados satisfatórios, tendo em vista que as formulações: F1 contendo (42,6 g de chia e 17,4 g de palma) e F4 contendo (30 g de chia) apresentaram índices de overrun próximo da média comercial. Além disso, a baixa incorporação de ar, quando comparada com os sorvetes comerciais, é comum em formulações artesanais (FREELAND-GRAVES \& PECKHAN 1996).

\section{Determinação da Taxa de Derretimento}

A taxa de derretimento das formulações de sorvetes estão apresentados na Figura 3. De acordo com Soler (2001), o sorvete drenado deve-se formar um líquido homogêneo com boa fluidez, com pouca espuma e apresentar a aparência do sorvete antes do congelamento.

Figura 3 - Taxa de derretimento do sorvete

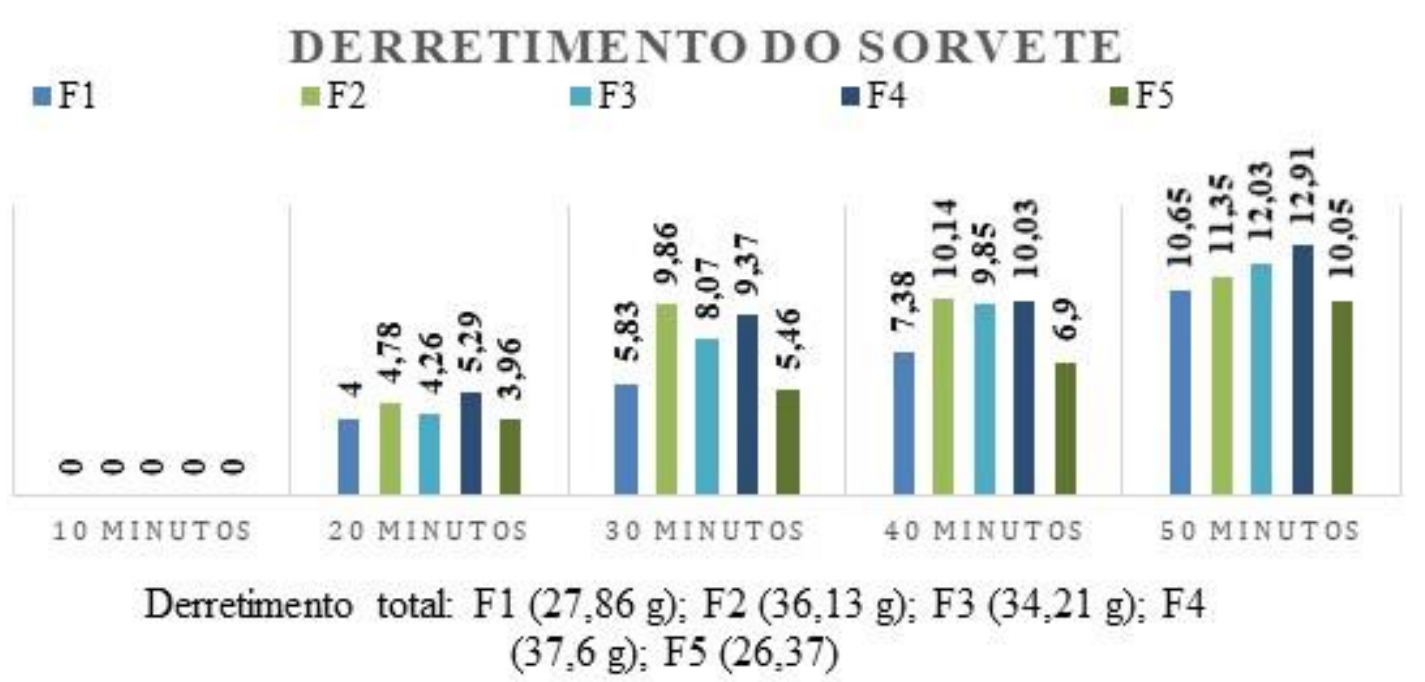

*F1-: Maior quantidade de chia e menor de palma; F2: Maior quantidade de palma e menor de chia; F3: Apenas palma; F4: Apenas chia; F5: Controle

Ao final da avaliação, a formulação que mais derreteu (50 min) foi a F4 (contendo apenas a mucilagem de chia), sendo a taxa de derretimento de 75,2\%, equivalente a 37,6g. Enquanto a formulação controle F5 (liga neutra) teve um derretimento de 26,37g do sorvete derretido, um percentual de 52,72\%.

Comparando as formulações F1, F2, F3 e F4, contendo as mucilagens de chia e palma com a formulação controle $\mathrm{F} 5$, podemos dizer que a formulação que se apresentou melhor foi a formulação F1 (42,6g de chia, 17,4g de palma), a qual teve um derretimento de 27,86g, um percentual de $55,72 \%$ próximo da formulação controle. 
Através do exame visual dos sorvetes durante a análise, foi possível perceber que não ocorreu derretibilidade total no tempo máximo estipulado (50 minutos). De acordo com o estudo de Soller e Veiga (2001) pode estar associado a quantidade de estabilizante empregado na formulação, neste caso representado pela mucilagem de chia e mucilagem de palma.

Sepúlveda et al., (2007) destacaram que a Opuntia spp. pode ser considerada uma fonte potencial de polissacarídeos (mucilagem) que poderiam ser aproveitadas como hidrocoloide pela indústria de alimentos. Damodaran (2007) menciona em seu estudo que ao adicionar hidrocolóides aos sorvetes esses retardam a taxa de desenvolvimento dos cristais de gelo, devido à elevação da viscosidade da fase líquida, desenvolvendo uma rede tridimensional o que diminui a mobilidade da água. Assim os sorvetes elaborados com a mucilagem de palma e chia apresentaram boa estabilidade, haja visto que os primeiros gotejamentos de todas as amostras ocorreram aos 20 minutos. Sendo este o tempo ideal para o início do derretimento em temperatura ambiente (SOLER, 2001).

\section{Conclusões}

A aplicação da mucilagem de chia e da palma na elaboração do sorvete de umbu se mostra viável por apresentarem resultados satisfatórios quanto à estabilidade do sorvete.

O sorvete elaborado neste estudo apresentou características físicas e físico-químicas adequadas. Haja vista, que os resultados obtidos estão dentro dos padrões estabelecidos na legislação vigente para overrun e sólidos solúveis.

A formulação que possui maior proporção de chia e menor de palma (Formulação 1), apresentou índice de overrun próximo ao controle, bem como próximo dos padrões comerciais.

Com base nos resultados obtidos neste estudo, pode-se afirmar que as mucilagens de chia e palma podem ser utilizadas como estabilizantes na fabricação de sorvetes, tendo em vista que o sorvete elaborado nesta pesquisa apresentou índices satisfatórios quanto ao rendimento e derretimento.

Dessa forma, a partir dos resultados, afirma-se que os sorvetes elaborados com mucilagem de palma e chia apresentam potencial, e deve ser explorado regionalmente valorizando matérias-primas regionais como a palma e o umbu.

\section{Recomendações}

Por ser um sorvete inovador, recomenda-se que diversos aspectos sejam melhorados, dessa maneira indica-se que sejam feitas mais análises do produto, a fim de avaliar outras características, aplicando para isso análises complementares, como as instrumentais de textura 
e plasticidade; viscosidade; avaliação de fibra alimentar; testes de composição proximal e avaliação sensorial, onde pode ser obtido resultados que incluem atributos como: Sabor, Textura, e Cor.

\section{Referências}

AOAC.ASSOCIATION OF OFFICIAL ANALYTICAL CHEMISTS.Oficial methods of analysis.16. Ed., Arlington.937p.

AOAC.ASSOCIATION OF OFFICIAL ANALYTICAL CHEMISTS.Oficial methods of analysis.18. Ed., Washington, 2005.

AUGUSTO, M. M. M.; FONTANA, C. V.; PADILHA, E.; RODRIGUES, A. P.; SILVESTRINI, M. Elaboração de sorvete sabor chocolate com teor de gordura reduzido utilizando soro de leite em pó. Rio Grande, 2006. Disponível em: https://periodicos.furg.br/vetor/article/viewFile/296/87. Acesso em: 27 ago. 2019.

BRASIL. Agência Nacional de Vigilância Sanitária - Anvisa. Resolução RDC n 267, de 25 de setembro de 2003 - Regulamento Técnico para Gelados Comestíveis e Preparos para Gelados Comestíveis, 2003.

BEZERRA, J. D; SANTOS, M. G; SVEDESE, V. M; LIMA, D. M; FERNANDES, M. J; PAIVA, L. M; MOTA, C. M. Richness of endophytic fungi isolated from Opuntia ficus-indica Mill. (Cactaceae) andpreliminaryscreening for enzyme production. World

Journal.Microbiol.Biotechnol.v. 28, p. 1989-1995, 2012.

BRASIL. Agência Nacional de Vigilância Sanitária - Anvisa. Portaria $n^{\circ}$ 266, de 22 de setembro de 2005- Regulamento Técnico para Gelados Comestíveis e Preparos para Gelados Comestíveis, 2005.

CARVALHO, P. C. L.; RITZINGER, R.; SOARES FILHO, W. S.; LEDO, C. A. S. Características morfológicas, físicas e químicas de frutos de populações de umbu cajazeira no estado da Bahia. Revista Brasileira de Fruticultura.140-147. 2008.

CLARKE, C. The Science of ice cream. Cambrige: Royal Society of Chemistry, 2004.

DAMODARAN, S. Inhibition of ice crystalgrowth in ice cream mix by gelatinhydrolysate. Journal of Agricultural and Food Chemistry. v. 55, p. 10918- 10923, 2007.

FELLOWS, Tecnologia do processamento de alimentos: princípios e prática. Porto Alegre: Artmed, 2006.

FERREIRA, J. C., CAVAlCANTI-MATA, M. E. R. M., BRAGA, M. E. D. Cinética de congelamento de polpa de umbu a duas temperaturas criogênicas In: Congresso Latino americana y del Caribe de Ingenieria Agrícola, 2000, Irapuato. Anais, 2000. 
FIDELIS. V. R. de L., PEREIRA. E. M., SILVA.W. P, GOMES. J. P., SILVA. L. A. Produção de sorvetes e iogurtes a partir dos frutos figo da índia e mandacaru. Revista Verde (Pombal PB - Brasil), VOL. 10. p. 17 - 21, 2015.

FREITAS, Aline. DESENVOLVIMENTO DE UM SORVETE DE ABACATE COM CALDA DE BANANA. 2012. $41 \mathrm{f}$. TCC (GRADUAÇÃO)- Curso de Tecnologia em Alimentos, Universidade Tecnológica Federal do Paraná, Ponta Grossa, 2012.

FREELAND-GRAVES, J. H.; PECKHAM, G. C. Foundations of Food Preparation.6. ed. New Jersey: Prentice-Hall, 1996.

GANDOLFI, Angela Maria Copini; MÜLLER, Terezinha Poposki. Elaboratingan ice cream addedwithhoneybee and Chia. 2014. 41 f. Trabalho de Conclusão de Curso (Graduação) Curso Superior de Tecnologia em Alimentos. Universidade Tecnológica Federal do Paraná. Francisco Beltrão, 2014.

GIULIETTI, A. M.; HARLEY, R. M.; QUEIROZ, L. P.; BARBOSA, M. R. V.; NETA, A. L. B.; FIGUEIREDO, M. A. Espécies endêmicas da caatinga. In: SAMPAIO, E.V.S.B.; GRANGER, C.; LEGER, A.; BAREY, P.; LANGENDORFF, V.; CANSELL, M. Influence of formulation on the structural networks in ice cream. InternationalDairy Journal, Barking, Inglaterra, v. 15, n. 3, p. 255-262, 2005.

GUSMÃO, Roberto da Silva. MÉTODOS EXTRATIVOS DE MUCILAGEM DE SEMENTE DE CHIA (Sálvia hispânica) PARA POTENCIAL USO EM OFTALMOLOGIA. 2016. 68 f. Dissertação (Mestrado) - Curso de Oftalmologia e Ciências Visuais, Unifesp - Universidade Federal de São Paulo, São Paulo, 2016.

LEE, J. C; et al. Antioxidant property of an ethanol extract of the stem of Opuntiaficusindicavar.saboten. Journal Agriculture Food Chemistry, n. 50, p. 6490-6496, 2002.

MUÑOZ, L. A. AGUILERA, J. M. RODRIGUEZ-TURIENZO, B. L.; COBOS, A, A.; DIAZ, A, O. Caracterization and microstructure of films made from mucilage of Salvia hispânica and whey protein concentrate. Journal of Food Engineering, v.111, p.511-518. 2012.

PINTO, Mirella. DESENVOLVIMENTO DE SORVETE À BASE DE POLPA DE MANDACARU E XIQUEXIQUE. 2017. 46 f. Dissertação (Graduação) - Instituto Federal de Educação e Tecnologia do Piaui, Teresina- Pi, 2017

REINOLDS, S. G.; ARIAS, E.; General background on Opuntia. Disponível em:<http://www.fao.org/ DOCREP /005/2808E/y2808e04.htm> Acesso em 26 de ago. 2019.

RODRIGUES, F. F. G.; NASCIMENTO, E. M. M.; FURTADO, C. A. N.; COSTA, J. G.M.. Análise físico-química de espécies de spondias oriundas do cariri cearense. Caderno de Culturas e Ciência. Vol. 1-Nº 2. 2010

SANTOS, C.A.F. Dispersão da variabilidade genética do umbuzeiro no semiárido brasileiro. Pesquisa Agropecuária Brasileira, v. 32, n. 6, p. 923-930, 1997. 
SEPÚLVEDA, E.; SÁENZ, C.; ALIAGA, E.; ACEITUNO, C. Extraction and characterization of mucilage in Opuntia spp. Journal of Arid Environments, v. 68, p. 534- 545, 2007.

SILVA. A. O. Elaboração de Sorvete e iogurte de leite de cabra com frutos do semiárido. Pág. 49. 2013.

SOLER, M. P. Sorvetes. Instituto de Tecnologia de Alimentos. Centro de Informação em Alimentos: Campinas, 2001, p. 36 e 37

SUDENE. Benefícios da cultura da palma. Disponível em: http://www.sudene.gov.br/redepalma/beneficios-da-cultura-da-palma. Acesso em: 29 de ago. 2019.

TECNOLOGIA DE ALIMENTOS. Disponível em: <http://tecalim.vilabol.uol.com.br/index.html>. Acesso em: 12.abr.2012.

TEIXEIRA, J. C; EVANGELISTA, A. R; PEREZ, J. R; TRINDADE, I. C. M; MORON, I. R. Cinética da digestão ruminal da palma forrageira (Nopalea cochenillifera (L.) Lyons-

Cactaceae) EM BOVINOS E CAPRINOS. Ciênc. e Agrotec, Lavras - Mg, v. 23, n. 1, p.179186,1999. Anual.

VALENTIM, Karina C.; SANTOS, Scheila C. Desenvolvimento de sorvete de baixa lactose com polpa de morango orgânico. Ponta Grossa, 2012. 